\title{
Micronutrients Versus Standard Medication Management in Autism: A Naturalistic Case-Control Study
}

\author{
Lewis Mehl-Madrona, M.D., Ph.D., M.Phil.,' Brenda Leung, N.D., M.Sc., Ph.D. (cand.), \\ Carla Kennedy, M.A., ${ }^{3}$ Sarah Paul, ${ }^{4}$ and Bonnie J. Kaplan, Ph.D.
}

\begin{abstract}
Autism spectrum disorder (ASD) is often accompanied by self-injurious behavior (SIB), aggression, and tantrums, symptoms that have reportedly improved with micronutrient (vitamins and minerals) treatment. The current study took advantage of naturally occurring differences in parental preferences for treatment approaches. The micronutrient group asked for treatment without pharmaceuticals ( $n=44$, aged 2-28 years at entry $[\mathrm{M}=8.39 \pm 5.58])$. Their records were matched with those of 44 similar children whose families requested conventional treatment (medication group). Both groups improved on both the Childhood Autism Rating Scale and the Childhood Psychiatric Rating Scale (all $p$ values $<0.0001$ ). Both groups also exhibited significant decreases in total Aberrant Behavior Checklist scores, but the micronutrient group's improvement was significantly greater $(p<0.0001)$. SIB Intensity was lower in the micronutrient group at the end of the study $(p=0.005)$, and improvement on the Clinical Global Impressions scale was greater for the micronutrient group $(p=0.0029)$. It is difficult to determine whether the observed changes were exerted through improvement in mood disorder or through an independent effect on autistic disorder. There were some advantages to treatment with micronutrients-lower activity level, less social withdrawal, less anger, better spontaneity with the examiner, less irritability, lower intensity SIB, markedly fewer adverse events, and less weight gain. Advantages of medication management were insurance coverage, fewer pills, and less frequent dosing.
\end{abstract}

\section{Introduction}

A UTISM SPECTRUM DISORDER (ASD) involves impaired social interactions and delayed language, as well as associated behavioral disturbances such as self-injurious behavior, aggression, and tantrums in response to routine environmental demands (Baghdadi et al. 2003). Increasingly, atypical antipsychotics (e.g., risperidone) are being used effectively in the treatment of tantrums and self-injurious behavior (SIB) (Canitano 2006; McDougle et al. 2008), but are often accompanied by adverse effects (Aman et al. 2005; Posey et al. 2008). In a summary of randomized controlled trials (RCTs) of medications used to treat aggression and SIB, only two (risperidone and methylphenidate) were beneficial in at least two trials (Parikh et al. 2008), suggesting there is room for further research and improvement in treatment strategies.

\section{Rationale for treatment with nutrients}

There are a variety of mechanisms by which vitamin and mineral supplementation (together known as micronutrients) might alter the expression of ASD symptoms. As discussed elsewhere (Kaplan et al. 2007), psychiatric symptoms may represent inborn metabolic dysfunction associated with slowed metabolic activity due to suboptimal availability of micronutrient cofactors (Ames et al. 2002). One approach to influencing metabolic efficiency that has been advocated for other disorders (Ames et al. 2002; Ames, 2003; Ames 2004) is to supplement patients with the vitamins and minerals that function as cofactors. Even single-defect genetic diseases have been shown to respond to micronutrient supplementation, the aim of which is to provide sufficient cofactor levels that even enzymes with drastically reduced Michaelis-Menten coefficients become supersaturated so that near-normal function is restored (Ames et al. 2002). Improved metabolic efficiency at the level of

\footnotetext{
${ }^{1}$ Department of Psychology, Argosy University, Honolulu, Hawaii, and Department of Family Medicine, University of Hawaii School of Medicine, Honolulu, Hawaii.

${ }^{2}$ Department of Community Health Sciences, University of Calgary Faculty of Medicine, Calgary, Alberta, Canada.

${ }^{3}$ Department of Anthropology, University of Manitoba, Winnipeg, Manitoba, Canada.

${ }^{4}$ School of Nursing, University of Saskatchewan, Saskatoon, Saskatchewan, Canada.

${ }^{5}$ Departments of Pediatrics, and Community Health Sciences, University of Calgary Faculty of Medicine, Calgary, Alberta, Canada.
} 
neurotransmitters is only one of several mechanisms that have been proposed to explain how micronutrients affect brain function. Others include enhanced antioxidant activity, improved bioenergetic function, improved methylation, and facilitation of mitochondrial function. It is possible that all of these mechanisms converge on a single, fundamental pathway, for which mitochondrial function is the likely candidate. It has been proposed that some psychiatric disorders, for instance, are actually mitochondrial diseases (Young 2007), because of demonstrated energy imbalance and mitochondrial dysfunction in schizophrenia and mood disorders (Kato and Kato 2000; Konradi et al. 2004; Gardner and Boles 2005).

\section{Nutrient interventions in autism}

There are many reports of high-potency, high-dose micronutrient therapy for a variety of neuropsychiatric and genetic disorders (Ames et al. 2002). Often these therapies are dismissed because of the smaller number of studies and perhaps also related to an intrinsic bias in favor of pharmaceuticals (Kemper and Hood 2008). Certainly, research funding is biased away from micronutrients because no new patents are possible among these compounds. However, reports do exist of treatment benefit for children with ASD, using nutrients such as pyridoxine (Ames et al. 2002). Sixteen autistic patients previously shown to respond to vitamin B6 treatment were reassessed and given vitamin B6 or a placebo in a double-blind study (Rimland et al. 1978). Behavior deteriorated significantly during B6 withdrawal, and 11 of 15 children exhibited improved behavior when given $300 \mathrm{mg}$ of vitamin B6/day. In questionnaires completed by 4,000 parents of autistic children, highdose vitamin B6 and magnesium treatment $(n=318)$ elicited the best response; for every parent reporting behavioral worsening with the treatment, 8.5 parents reported behavioral improvement. The next best results were with the acetylcholine precursor, deanol $(n=121) ; 1.8$ parents reported a favorable response for every parent who reported worsening (Rimland 1988). Further support from a study of 33 children with pervasive developmental disorder (PDD) supplemented with magnesium-B6 supplement showed improved symptoms for social interaction, communication, stereotyped restricted behavior, and abnormal/delayed functioning compared to controls (Mousain-Bosc et al. 2006). However, a Cochrane systematic review on the vitamin B6-magnesium combination for treating ASD concluded that because of the small number of studies, small sample sizes, and uncertain methodological quality, vitamin B6-magnesium combination could not be recommended for the treatment of ASD (Nye and Brice 2005).

Recently, positive open-label results have been reported for other B vitamins (James et al. 2009) and for fish oil (Meguid et al. 2008). In addition, a double-blind RCT using a moderate-dose multivitamin/ mineral supplement in children with ASD found improvement in sleep and gastrointestinal symptoms using the Global Impression parental questionnaire (Adams and Holloway 2004). Unfortunately this was a pilot study, with small sample size and absence of objective measure of behavior to truly assess changes between the two groups.

\section{Nutrient interventions for aggression and unstable mood}

Outside of the population of ASD, there is also a growing literature on the use of nutritional treatment of irritability, aggression, and mood swings. As recently reviewed (Kaplan et al. 2007), 100 years of scientific research on single-nutrient interventions have provided some promising (though modest) results. In contrast, research since 2000 on multinutrient formulas has shown much larger effects. An older version of the 36-ingredient supplement used in the current study has been the topic of other investigations. Four were open-label investigations in adults, adolescents, and children with bipolar disorder (BPD) (Kaplan et al. 2001; Popper 2001; Simmons 2002; Kaplan et al. 2004). In addition, 2 children with developmental disabilities (one on the autism spectrum) were studied in within-subject cross-over designs: On-off control of their tantrums and rages was demonstrated with these micronutrients (Kaplan et al. 2002). Recently, two additional reports have been published, and one is in press. In a database analysis of a large sample of 358 adults with BPD, more than half were positive responders (defined as $>50 \%$ decrease in symptom severity) after 3 months of consuming this micronutrient formula (Gately and Kaplan 2009). Importantly, their symptom improvement was sustained at 6 months, making it unlikely that placebo or expectancy effects accounted for the reported changes. Also in 2009, an unusual case report of an 18-year-old boy with obsessive-compulsive disorder (OCD) was published with historical data showing his response to cognitive behavior therapy (Rucklidge 2009). Subsequently, he was treated with the 36-ingredient formula in an $\mathrm{ABAB}$ design, which resulted in on-off control of anxiety and mood symptoms (Rucklidge 2009). Finally, a case has been reported of a child diagnosed with BPD and with 6 years of well-documented pharmaceutical treatments for his psychiatric symptomatology (Frazier et al. 2009). At the age of 12, the boy's family chose to transition him from medication onto the micronutrient formula, which was accomplished in 19 days; subsequently, most of his symptoms have resolved.

The characteristic that all these reports have in common is that broad-spectrum micronutrient treatment resulted in improved mood stability, but this particular formula is not, of course, the only one being used for this purpose. For instance, an RCT showed that a 25-ingredient micronutrient formula plus some omega-3 fatty acids (eicosapentaenoic acid [EPA] and docosahexaenoic acid [DHA]) resulted in roughly a one-third reduction of aggressive offenses in young adult prisoners (Gesch et al. 2002).

Omega-3 fatty acid supplementation studies have thus far reported mixed results. An Austrian group conducted a 6-week RCT in 13 children with ASD, comparing 1.5 grams/day of omega-3 fatty acids to placebo (Amminger et al. 2007). Although the treatment group's changes on the Aberrant Behavior Checklist $(\mathrm{ABC})$ failed to reach statistical significance, the authors interpreted their findings as being positive. In other studies with omega3 fatty acid supplementation, 12 weeks of supplements did not alter aggression or hostility in 49 patients with recurrent SIB, although depression and suicidality were ameliorated (Hallahan et al. 2007). Physical aggression in school boys also was not ameliorated with about 514 grams/day over 3 months (Itomura et al. 2005). However, as mentioned above, Meguid and colleagues reported clinical benefit in two-thirds of their sample of 30 children with ASD who consumed fish oil (Meguid et al. 2008).

This paper takes advantage of naturally occurring differences in parental preferences for treatment approaches within the senior author's psychiatric practice: One group requested the psychiatrist's assistance in addressing the problems of their autistic children without pharmaceuticals, and the other sought conventional psychopharmacological treatment with little interest in alternative therapies. This natural separation of two relatively distinct groups provided the opportunity to compare the outcomes that can be achieved by these two different management styles. This paper reports the results of that comparison, using case-control methodology in a naturalistic clinic setting. 


\section{Methods}

\section{Design}

The current case-control study compared two management styles used by a single psychiatrist (L.M.-M.), in clinical settings where families had the same goal of optimizing their children's function and reducing disturbing symptoms. They differed in their beliefs about how to reach that goal: One group wanted to avoid pharmaceuticals, and the other requested optimization of their child's medication. The importance of patients and families guiding their choices with practitioner feedback has been discussed elsewhere (Mehl-Madrona 2007). The alternative treatment was provided at the request of parents, who signed standard clinical consent forms for treatment. Patient assent was obtained in those cases where it was clinically appropriate.

Several factors facilitated this group comparison: (1) Unlike many clinical environments, this psychiatrist always employs objective measures of his patients' symptoms; (2) at the time these patients were in treatment, the psychiatrist held no intrinsic bias for or against either type of intervention, but only focused on optimizing the treatment approach that fit the beliefs and values of each family; (3) it was possible to have the data analyzed objectively by individuals (B.L. and B.J.K.) in a different geographical region who were not connected in any way with the patients or the clinics.

\section{Participants}

From his clinical records from 1998 to 2008, the first author recovered the charts of all the children diagnosed with ASD whose parents had requested therapy without pharmaceuticals and for whom outcome data were complete. There were 44 with complete records ( 8 others that were incomplete were excluded), ranging in age from 2 to 28 years at entry $(M=8.39$, standard deviation $[\mathrm{SD}]=5.58)($ Table 1$)$. The clinician then matched those children with the records from his files of 44 similar children whose families had requested conventional, pharmaceutical treatment. Matching variables consisted of age ( \pm 1 year), sex, parental education and income, intelligence quotient (IQ) (by category), and symptom severity as measured on the Clinical Global Impressions (CGI) scale. The only other requirement was the presence of a complete set of outcome data for at least 3 months. Length of follow up varied considerably, but did not differ between the two groups (Table 1). Most $(n=66)$ were seen in university-affiliated clinics, and the remainder in private practice. The sample was primarily Caucasian (>80\%) and urban. The sample was mostly pediatric: $86 \%$ of the micronutrient group and $77 \%$ of the medication group were $\leq 12$. The micronutrient group also included 3 adolescents and 3 patients aged 18 or over; the medication group included 3 adolescents and 7 adults. Seventy-three percent and $66 \%$ of the micronutrient and medication groups, respectively, were on medication at the time of referral.

\section{Confirmation of diagnosis}

All children seen in this practice arrived with a preexisting diagnosis, often by several physicians, and all had received extensive evaluations and were receiving multiple additional services (e.g., occupational therapy, educational assistance). The first author

Table 1. Baseline Characteristics

\begin{tabular}{|c|c|c|c|}
\hline Characteristic & Micronutrient group $(\mathrm{n}=44)$ & Medication group $(\mathrm{n}=44)$ & \\
\hline $\begin{array}{l}\text { Age }(\mathrm{M}[\mathrm{SD}] \text { in years) } \\
\text { (range) }\end{array}$ & $\begin{array}{c}8.39(5.58) \\
\quad(2-28)\end{array}$ & $\begin{array}{l}9.40(6.20) \\
\quad(2-27)\end{array}$ & $t=-0.81, p=0.42$ \\
\hline $\operatorname{Sex}(n[\%$ total $])$ & $\begin{array}{c}\text { Male }=32(73 \%) \\
\text { Female }=12(27 \%)\end{array}$ & $\begin{array}{l}\text { Male }=36(82 \%) \\
\text { Female }=8(18 \%)\end{array}$ & $\chi^{2}=1.03, p=0.31$ \\
\hline $\begin{array}{l}\text { Number of medications } \\
\text { used at entry (M [SD]) }\end{array}$ & $1.79(1.41)$ & $1.70(1.49)$ & $t=0.29, p=0.77$ \\
\hline $\begin{array}{l}\text { Follow-up length (M [SD] } \\
\text { in months) } \\
\text { (range) }\end{array}$ & $\begin{array}{c}23.97(21.24) \\
(3-98)\end{array}$ & $\begin{array}{c}18.02(18.47) \\
(3-84)\end{array}$ & $t=1.40, p=0.16$ \\
\hline $\begin{array}{l}\text { Family income }(n) \\
\quad<\$ 20,000 \\
20,001-40,000 \\
40,001-60,000 \\
>60,001\end{array}$ & $\begin{array}{r}14 \\
8 \\
14 \\
8\end{array}$ & $\begin{array}{r}15 \\
9 \\
11 \\
9\end{array}$ & $\chi^{2}=0.51, p=0.92$ \\
\hline $\begin{array}{l}\text { Caretaker education } \\
\quad(\mathrm{M}[\mathrm{SD}] \text { in years }) \\
\leq 12 \text { years }(n) \\
\leq 16 \text { years }(n) \\
\geq 17 \text { years }(n)\end{array}$ & $\begin{array}{l}14.86(3.10) \\
10 \\
19 \\
15\end{array}$ & $\begin{array}{c}14.52(3.26) \\
14 \\
16 \\
14\end{array}$ & $\begin{array}{l}t=0.50, p=0.62 \\
\chi=7.58, p=0.75\end{array}$ \\
\hline Child IQ (M [SD]) & $88.75(25.78)$ & $91.29(27.51)$ & $t=-0.45, p=0.66$ \\
\hline Micronutrient type & $\begin{array}{l}\text { EMPower }(n=15) \\
\text { EMPowerplus }(n=14) \\
\text { Customized to match } \\
\quad \text { EMPowerplus }(n=10) \\
\text { Prenatal }(n=5)\end{array}$ & None $(n=44)$ & N.A. \\
\hline
\end{tabular}


completed his own clinical assessment as well, and confirmed the diagnosis based on interview, history, and questionnaires. All children met the criteria for autistic disorder described in the Diagnostic and Statistical Manual of Mental Disorders, $4^{\text {th }}$ edition (DSM-IV) (American Psychiatric Association 1994), with tantrums, aggression, SIB, or a combination of these problems. All children had a mental age of at least 18 months, on the basis of records of prior assessments.

\section{Physical and laboratory assessments}

Baseline assessments consisted of history, neurological, and physical examinations that included height, weight, heart rate, and blood pressure for older children. Screening procedures included a complete blood cell count (CBC); measurement of electrolytes, blood urea nitrogen, fasting glucose, creatinine; liver function tests; and urinalysis. Each child had received a magnetic resonance imaging (MRI) scan or computed tomography (CT) scan at some time to confirm structural normality on that diagnostic procedure. All values were within normal limits, and remained there regardless of the intervention administered.

\section{Micronutrient management}

The clinician selected a broad-based micronutrient supplement that encompassed all known dietary vitamins and a broad spectrum of minerals and trace elements. 1 Twenty-nine children took this supplement or its older version. (Developed by Truehope Nutritional Support Ltd., the supplement was initially called EMPower. In 2002 the company changed manufacturers to use methods that decreased the number of capsules and improved the bioavailability of the product. The resulting product has the same 36 ingredients, but was given the new name of EMPowerplus. The current formula can be found on the developer's website [Truehope.com]. It consists of all 14 of the known vitamins, 16 dietary minerals, 3 amino acids, and 3 antioxidants.) The parents of 10 children had preferences for other brands, so the clinician guided them to try to match the micronutrient formula while accommodating their brand loyalty (in Table 1, "customized" supplement). Finally, the parents of 5 children could not afford to purchase any supplements, so they were prescribed prenatal formulas (covered by their health insurance plan) in doses that approximated the micronutrient formula. Hence, 39 of the 44 children took similar broad-spectrum supplements; 5 of the children took the prenatal formulas. The clinician typically attempted to reduce their medications by $10-25 \%$ at each visit (listed below in Table 7).

\section{Medication management}

The clinician's goal was to find the minimum dose that would bring symptoms to acceptable levels with an acceptable side effect profile. Mean number of medications changed from 1.7 to 2.5 over the course of treatment (listed below in Table 7).

\section{Management common to both groups}

Every patient's treatment was initiated after a "roundtable of healing," where relatives and interested friends discussed options and decided upon a treatment plan (Mehl-Madrona 2007). Often those groups continued to meet occasionally, as part of an ongoing "healing circle" (Mehl-Madrona 2007). Families were also encouraged to continue other resources. As a matter of general health, fish oil (not present in the micronutrient formula) was recommended to all families, in doses of at least 2,000 $\mathrm{mg}$ EPA for a 50-kg person and scaled down according to weight to $400 \mathrm{mg}$ for a $10-\mathrm{kg}$ child. Because this was a naturalistic study, there was no attempt to control other supplements that the families experimented with from time to time, but they were reported and analyzed.

\section{Measures}

Behavioral symptoms were assessed by multiple raters (parents, teachers, and/or other caregivers) and averaged. Because follow up was variable (Table 1), we report here the differences between baseline and final evaluation. The Childhood Autism Rating Scale (CARS) (Schopler et al. 1980) is a 15-item scale measuring autistic behavior, and is sensitive to treatment effects (Masi et al. 2001). A 14-item subset of the Children's Psychiatric Rating Scale (CPRS) (Fish 1985) has proven useful for assessing behavior in autistic children (Overall and Campbell 1988) and is sensitive to medication effects (Campbell and Palij 1985). The five scales of the Aberrant Behavior Checklist (ABC) (Aman et al. 1985) have been used often to monitor an array of behaviors; reliability and validity are high (Marshburn and Aman 1992). The Yale-Paris Self-Injurious Behavior Scale (YAPA-SIB) was used to rate the current pattern of behavior (Canitano 2006), indicating severity, frequency, and duration. The clinician rated severity of behavior from 1 (normal, not at all ill) to 7 (extremely ill) on the CGI scale (Guy 1976).

\section{Results}

The two groups were well matched at baseline (Table 1). The Cohen $d$ for nonindependent samples was used to estimate effect sizes: Difference between mean symptom severity pretreatment to posttreatment, divided by the SD of the difference score. The $p$ values in the following tests have been adjusted with the Bonferroni correction for multiple tests.

\section{CARS}

Treatment benefit was shown for both groups on the total CARS (Table 2): Micronutrient group, $t(43)=8.07, p<0.0001$; medication group, $t(43)=8.06, p<0.0001$. The change in total CARS score did not differ between groups, $t(86)=-0.63, p=0.53$. Of the 15 scale items, the only group difference was in Activity Level $(t(86)=3.31, p=0.001)$, with the micronutrient group showing a larger change, micronutrient group $d=1.46$, medication group $d=1.04$.

\section{CPRS}

Both groups exhibited significant reductions in total CPRS (Table 3): Micronutrient group, $t(43)=9.69, p<0.0001$; medication group, $t(43)=11.00, p<0.0001$, with no group difference in treatment effects, $t(86)=-1.32, p=0.19$.

The individual items within the CPRS were examined for patterns, as done elsewhere (Masi et al. 2001). The overall model was significant, using multivariate analysis of variance (MANOVA) (Wilks lambda $\mathrm{F}[14,73]=5.52, p<0.0001)$. Post hoc tests confirmed that group (micronutrient versus medication) had an effect on the subscales of withdrawal, angry affect, and unspontaneous relation to examiner $(\mathrm{F}(3,86)=9.74, p<0.0001)$. Significant group differences in treatment effects were found for all three of those characteristics: Withdrawal $(t[84]=2.37, p=0.020)$ (micronutrient group, $d=1.26$; medication group, $d=0.88$ ), angry affect $(t[84]=4.09, p<0.0001)$ (micronutrient group, $d=1.27$; 
Table 2. Childhood Autism Rating Scale

\begin{tabular}{|c|c|c|c|c|}
\hline & \multicolumn{2}{|c|}{ Micronutrient group } & \multicolumn{2}{|c|}{ Medication group } \\
\hline & Baseline & Final & Baseline & Final score \\
\hline Total score ${ }^{\mathrm{a}}$ & $48.79(7.19)$ & $30.68(15.79)$ & $46.38(5.59)$ & $30.18(13.38)$ \\
\hline Relating to people & $3.45(0.95)$ & $1.95(1.88)$ & $3.18(0.81)$ & $1.86(1.13)$ \\
\hline Imitation & $3.20(0.88)$ & $2.02(1.34)$ & $3.20(1.04)$ & $2.11(1.14)$ \\
\hline Emotional response & $3.55(1.00)$ & $1.95(1.31)$ & $3.11(0.87)$ & $1.77(1.32)$ \\
\hline Body use & $3.20(0.90)$ & $2.07(1.30)$ & $3.13(0.82)$ & $1.93(1.17)$ \\
\hline Object use & $3.20(0.93)$ & $1.95(1.26)$ & $3.15(0.78)$ & $1.75(1.24)$ \\
\hline Adaptation to change & $3.20(1.02)$ & $1.98(1.32)$ & $3.16(0.99)$ & $1.75(1.03)$ \\
\hline Visual response & $2.73(0.45)$ & $2.02(0.92)$ & $2.95(0.91)$ & $2.09(1.25)$ \\
\hline Listening response & $2.80(0.79)$ & $1.93(1.10)$ & $2.45(0.66)$ & $1.77(1.05)$ \\
\hline Taste, smell, touch & $2.68(0.91)$ & $1.88(1.00)$ & $2.25(0.78)$ & $1.81(1.33)$ \\
\hline Fear or nervousness & $3.22(1.03)$ & $1.31(1.24)$ & $3.25(0.84)$ & $2.22(1.07)$ \\
\hline Verbal communication & $3.50(0.66)$ & $1.19(1.14)$ & $3.84(1.09)$ & $3.16(1.26)$ \\
\hline Nonverbal communication & $3.88(0.92)$ & $2.52(1.19)$ & $2.90(1.29)$ & $1.88(1.06)$ \\
\hline Activity level ${ }^{\mathrm{b}}$ & $3.98(0.73)$ & $2.05(1.63)$ & $3.18(1.35)$ & $2.09(1.34)$ \\
\hline Intellectual response & $2.34(0.91)$ & $1.30(1.32)$ & $2.98(1.02)$ & $1.77(1.20)$ \\
\hline General impression & $3.84(1.62)$ & $2.36(1.57)$ & $3.61(0.78)$ & $2.18(1.40)$ \\
\hline
\end{tabular}

Mean scores for both groups, with standard deviations (SDs) in parentheses.

${ }^{\mathrm{a} B}$ Both groups improved with treatment, $p<0.0001$, with no group difference.

${ }^{\mathrm{b}}$ For this one item, the improvement for the micronutrient group $(d=1.46)$ was significantly greater than the change for the medication group $(d=1.04), p=0.001$.

medication group, $d=0.72$ ), and unspontaneous relation to examiner $(t[84]=4.86, p<0.0001)$ (micronutrient group, $d=1.35$; medication group, $d=0.42$ ).

\section{Aberrant behavior checklist}

Although both groups exhibited significant decreases in the total ABC scores (Table 4), the change for the micronutrient group $(t[43]=17.42, p<0.0001)$ was greater than for the medication group $(t[43]=14.14, p<0.0001)$, group difference, $t[86]=-4.01$, $p=0.0001)$.

The overall model using MANOVA was significant: Wilks lambda $\mathrm{F}=3.79, p=0.0022$. Post hoc tests confirmed a group difference on the changes in the $\mathrm{ABC}$ score: $\mathrm{F}(6,86)=4.02, p=0.0013$. Of the five subscales, the changes in two differed by group: Irritability $(t[86]=-4.09, p=0.0001)$ (micronutrient group, $d=1.66$; medication group, $d=1.02)$ and hyperactivity $(t[86]=-2.51, p=0.014)$ (micronutrient group, $d=1.97$; medication group, $d=1.53$ ).

Table 3. Children's Psychiatric Rating Scale

\begin{tabular}{|c|c|c|c|c|}
\hline & \multicolumn{2}{|c|}{ Micronutrient group } & \multicolumn{2}{|c|}{ Medication group } \\
\hline & Baseline & Final & Baseline & Final \\
\hline Total score $^{\mathrm{a}}$ & $55.93(5.24)$ & $32.43(15.88)$ & $53.36(4.86)$ & $33.84(12.19)$ \\
\hline Underproductive speech & $6.70(2.99)$ & $4.04(2.25)$ & $7.23(2.22)$ & $4.28(2.22)$ \\
\hline Fidgetiness & $4.41(1.19)$ & $2.38(1.64)$ & $4.30(0.90)$ & $1.77(1.34)$ \\
\hline Hyperactivity & $4.66(1.01)$ & $2.05(1.57)$ & $4.20(0.82)$ & $1.82(1.48)$ \\
\hline Hypoactivity & $0.73(1.02)$ & $0.57(1.00)$ & $0.52(1.02)$ & $0.91(1.82)$ \\
\hline Abnormal object relationships & $4.93(0.95)$ & $2.95(1.52)$ & $5.34(1.39)$ & $3.18(1.59)$ \\
\hline Withdrawal $^{\text {b }}$ & $5.11(0.95)$ & $3.02(1.62)$ & $4.18(0.99)$ & $2.89(1.39)$ \\
\hline Negative, uncooperative & $4.57(0.95)$ & $2.64(1.56)$ & $4.23(0.94)$ & $2.06(1.25)$ \\
\hline Angry affect ${ }^{\mathrm{c}}$ & $3.35(1.09)$ & $1.70(1.24)$ & $3.11(0.99)$ & $2.45(1.22)$ \\
\hline Unspontaneous relation to examiner ${ }^{\mathrm{d}}$ & $5.35(0.76)$ & $3.14(1.79)$ & $5.23(0.71)$ & $4.61(1.22)$ \\
\hline Lability of affect & $4.57(0.79)$ & $2.80(1.60)$ & $4.02(0.79)$ & $2.80(1.13)$ \\
\hline Low voice & $0.64(1.14)$ & $0.57(1.00)$ & $0.77(1.01)$ & $0.55(0.90)$ \\
\hline Loud voice & $2.25(1.48)$ & $1.32(1.25)$ & $2.15(1.31)$ & $1.70(1.46)$ \\
\hline Other speech deviance & $3.75(1.40)$ & $2.50(1.41)$ & $4.25(1.33)$ & $2.93(1.26)$ \\
\hline Rhythmic motions (stereotypic) & $4.91(1.23)$ & $2.75(1.68)$ & $3.82(1.47)$ & $2.09(1.46)$ \\
\hline
\end{tabular}

Mean scores for both groups, with standard deviations (SDs) in parentheses.

${ }^{a}$ Both groups improved with treatment, $p<0.0001$, with no group difference.

${ }^{\mathrm{b}}$ The change from baseline for the micronutrient group $(d=1.26)$ was greater than the change for the medication group $(d=0.88), t=2.37, p=0.020$.

${ }^{\mathrm{c}}$ The change from baseline for the micronutrient group $(d=1.27)$ was greater than the change for the medication group $(d=0.72), t=4.86, p<0.001$.

${ }^{\mathrm{d}}$ The change from baseline for the micronutrient group $(d=1.35)$ was greater than the change for the medication group $(d=0.42), t=4.09, p<0.001$. 
Table 4. Aberrant Behavior Checklist

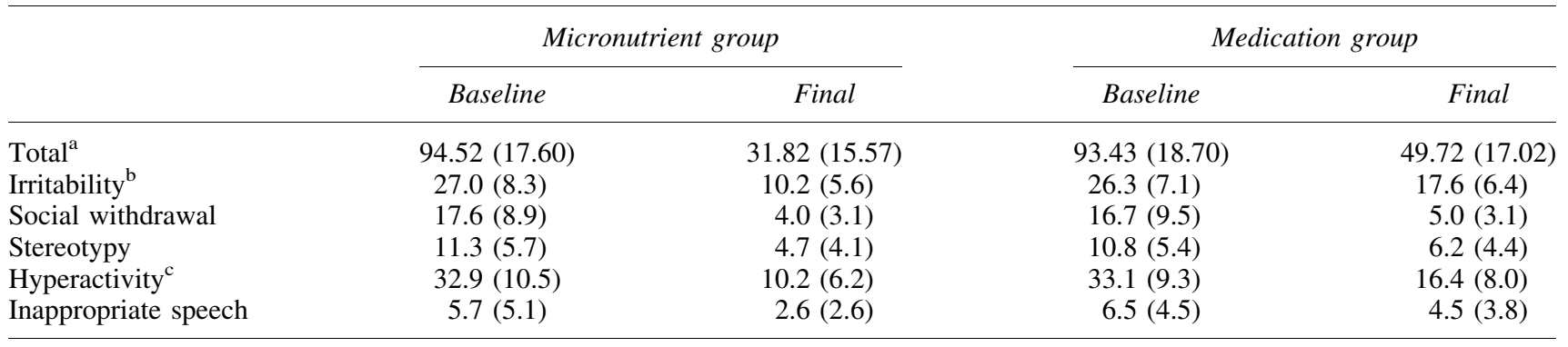

Mean scores for both groups, with standard deviations (SDs) in parentheses.

${ }^{a}$ Both groups improved with treatment, $p<0.0001$, but the change for the micronutrient group was greater than for the medication group, $p=0.0001$.

${ }^{\mathrm{b}}$ The change from baseline for the micronutrient group $(d=1.66)$ was greater than the change for the medication group $(d=1.02), t=4.09, p=0.0001$.

${ }^{\mathrm{c}}$ The change from baseline for the micronutrient group $(d=1.97)$ was greater than the change for the medication group $(d=1.53), t=2.51, p=0.014$.

\section{Self-injurious behavior}

There was no difference in the changes in frequency of SIB for the two groups from start $\left(\chi^{2}=0.47, p=0.79\right)$ to end $\left(\chi^{2}=0.55, p=0.76\right)$ (Table 5). However, SIB intensity, while similar for the two groups at baseline, $\chi^{2}=0.20, p=0.90$, was lower in the micronutrient group at the end $\left(\chi^{2}=7.72, p=0.005\right)$. Baseline values of duration were reported only at the extremes of 1 and 7 , preventing proper analysis.

\section{Clinical global impressions}

Although the CGI is a categorical variable, it was analyzed as a continuous variable, as is often done. The micronutrient group's CGI decreased from $3.84 \pm 1.75$ to $2.48 \pm 1.56, d=0.82$; the medication group's CGI remained constant, from $3.84 \pm 1.75$ to $3.86 \pm 1.59, d=-0.013$. The improvement on the CGI was significantly greater for the micronutrient group, $t(84)=-3.0647$, $p=0.0029$.

\section{Covariates}

Multiple regression analysis was used to assess the baseline characteristics of age, sex, parental education, child's IQ, and income

Table 5. Yale-Paris Self-Injurious Behavior

\begin{tabular}{|c|c|c|c|}
\hline $\begin{array}{l}\text { Self-injurious } \\
\text { behavior }\end{array}$ & $\begin{array}{l}\text { Micronutrient } \\
\text { group }(\mathrm{n})\end{array}$ & $\begin{array}{l}\text { Medication } \\
\text { group }(\mathrm{n})\end{array}$ & $\chi^{2} \mathrm{p}$ value \\
\hline \multicolumn{4}{|l|}{ Frequency } \\
\hline None & 16 & 13 & \multirow[t]{3}{*}{$\chi^{2}=0.4680 p=0.791$} \\
\hline Mild & 16 & 18 & \\
\hline High & 12 & 13 & \\
\hline \multicolumn{4}{|l|}{ Intensity } \\
\hline None & 16 & 15 & \multirow[t]{3}{*}{$\chi^{2}=0.2001 p=0.905$} \\
\hline Mild & 21 & 23 & \\
\hline High & 7 & 6 & \\
\hline \multicolumn{4}{|l|}{ Final } \\
\hline \multicolumn{4}{|l|}{ Frequency } \\
\hline None & 21 & 20 & \multirow[t]{3}{*}{$\chi^{2}=0.5500 p=0.760$} \\
\hline Mild & 20 & 19 & \\
\hline High & 3 & 5 & \\
\hline \multicolumn{4}{|l|}{ Intensity $^{\mathrm{a}}$} \\
\hline None & 30 & 17 & \multirow[t]{3}{*}{$\chi^{2}=7.7177 p=0.005$} \\
\hline Mild & 14 & 27 & \\
\hline High & - & - & \\
\hline
\end{tabular}

a The change in intensity from baseline to the final appointment was significant only for the micronutrient group. on each scale or subscale of the CARS, CPRS, ABC, or CGI with significant treatment outcomes. None was a significant predictor. Post hoc comparisons of the three supplement subtypes did not reveal any significant differences on the outcome on the CGI.

\section{Role of omega-3 supplements}

At the final appointment, 24 in the micronutrient group and 8 in the medication group reported using fish oil, so the question asked was whether this difference accounted for any of the treatment effects obtained. A multiple regression analysis of intervention group, supplement subtype and fish oil with the outcome CGI found no effect of fish oil $(t[84]=0.56 p=0.57)$. A second model using the same predictor variables on the outcome $\mathrm{ABC}$ total also found no effect of fish oil $(t[84]=0.62, p=0.53)$.

A logistic regression analysis on SIB intensity using intervention group, supplement subtypes, and fish oil as predictor variables resulted in a significant finding for fish oil $(z=-2.38, p=0.017)$; however, further stratified analysis showed nonsignificant results for fish oil on SIB intensity by intervention group (micronutrient group $\left.\chi^{2}(1)=2.94, p=0.087\right)$, medication group $\chi^{2}(1)=2.35$, $\mathrm{p}=0.125)$. The inconsistent results may be due to reduced numbers in some cells in the stratified analysis (i.e., $<5$ ), which resulted in reduced power, or because the rating for the item SIB intensity was reduced from five categories at the start of the study to two categories at the end.

\section{Medication use}

The groups differed in number of medications at the end as a result of clinical management $(t=-6.1867, p<0.0001)$ : Micronutrient group $(\mathrm{M}=0.59$, SD 0.95$)$, medication group $(\mathrm{M}=2.23$, SD 1.48) (Table 7). The group difference was significant, $t=-6.1867, p<0.0001$ : Micronutrient group $(\mathrm{M}=0.59, \mathrm{SD}$ $0.95)$, medication group ( $M=2.23$, SD 1.48). The number of pills consumed per day was about 1-6 for the medication group and 4-18 for the micronutrient group.

\section{Adverse events}

The micronutrient group had 33 adverse events, compared to 214 in the medication group. Of the 22 types of adverse events reported, 9 categories were significantly less common in the micronutrient group than the medication group (Table 6); in no case was an adverse event reported more often by the micronutrient group. Furthermore, the average weight gain was significantly less in the 
micronutrient group $(\mathrm{M}=0.80 \mathrm{~kg}$, SD 1.02) compared to the medication group $(\mathrm{M}=3.50, \mathrm{SD} 2.59), t(86)=-6.41, p<0.0001$.

\section{Other treatments}

Other nutrient supplements (e.g., vitamin E, inositol, individual amino acids) were reported in 22 children in the micronutrient group compared to 6 in the medication group. At the final appointment, the mean number of other supplements did not differ by group: Micronutrient group $=5.36$ (range 0-17), medication group $=4.00$ (range 0-9). The use of other therapies (e.g., occupational therapy) also did not differ between groups, $t(86)=1.14$, $p=0.25$.

\section{Discussion}

The most salient finding from this comparison of two groups of well-matched children and young adults with ASD is that it was possible to achieve comparable symptom management with both micronutrients and pharmaceuticals. In no case was any advantage detected for pharmaceutical management in terms of symptoms. In contrast, micronutrient management resulted in the following significant advantages: Lower activity level (found on two measures), less social withdrawal, less anger, better spontaneity in relation to the examiner, less irritability, lower intensity of SIB, markedly fewer adverse events, and less weight gain. There were, however, three advantages of medication management: Insurance coverage, fewer pills, and less frequent dosing.

Several other points should be noted: (1) Baseline symptom severity scores on the CARS, CPRS, and ABC were comparable to other published samples (Masi et al. 2001; Canitano 2006; Amminger et al. 2007); (2) the magnitude of improvement on the CPRS for the medication group (about 20 points) greatly exceeded the magnitude reported from an open-label trial of risperidone (about 11 points) (Masi et al. 2001), indicating that

Table 6. Adverse Events

\begin{tabular}{lccc}
\hline Adverse event & $\begin{array}{c}\text { Micronutrient } \\
\text { group }(\mathrm{n})\end{array}$ & $\begin{array}{c}\text { Medication } \\
\text { group }(\mathrm{n})\end{array}$ & $\begin{array}{c}\text { Group difference } \\
\text { p value }\end{array}$ \\
\hline Increased appetite & 1 & 32 & $<0.0001$ \\
Fatigue & 1 & 29 & $<0.0001$ \\
Drowsiness & 1 & 31 & $<0.0001$ \\
Vomiting & 1 & 9 & 0.015 \\
Anxiety & 6 & 19 & 0.004 \\
Diarrhea & 4 & 5 & 1.000 \\
Constipation & 0 & 6 & 0.026 \\
Sleep problems & 1 & 4 & 0.360 \\
Drooling & 0 & 4 & 0.116 \\
Headache & 2 & 8 & 0.089 \\
Stomach ache & 9 & 9 & 1.000 \\
Dry mouth & 0 & 6 & 0.026 \\
Increased thirst & 0 & 5 & 0.055 \\
Dizziness & 0 & 5 & 0.055 \\
Dyskinesia & 0 & 7 & 0.012 \\
Nausea & 3 & 5 & 0.713 \\
Decreased appetite & 2 & 5 & 0.434 \\
Tremor & 2 & 8 & 0.089 \\
Tachycardia & 0 & 4 & 0.116 \\
Muscle rigidity & 0 & 4 & 0.116 \\
Restlessness & 0 & 3 & 0.241 \\
Akisthesia & 0 & 6 & 0.026 \\
\hline
\end{tabular}

${ }^{\mathrm{a}} p$ values obtained from Fisher exact test.
Table 7. Number of Medications Prescribed at The BeginNing (AND End) of the Study

\begin{tabular}{lcc}
\hline Medication type & $\begin{array}{c}\text { Micronutrient } \\
\text { group }\end{array}$ & $\begin{array}{c}\text { Medication } \\
\text { group }\end{array}$ \\
\hline Neuroleptic & $21(6)$ & $18(20)$ \\
SSRI & $19(5)$ & $28(24)$ \\
Mood stabilizer & $16(4)$ & $3(22)$ \\
Stimulant & $13(6)$ & $16(23)$ \\
$\begin{array}{l}\alpha \text {-Adrenergic } \\
\text { blocker (e.g., clonidine) }\end{array}$ & $10(2)$ & $10(2)$ \\
Buproprion & $0(3)$ & $0(7)$ \\
\hline
\end{tabular}

Abbreviations: $\mathrm{SSRI}=$ Selective serotonin reuptake inhibitor.

the clinician for the current study competently optimized medications; (3) the published adverse event rates for risperidone (Aman et al., 2005) were virtually nonexistent in the micronutrient group (Table 6); and (4) there were similarities in the symptoms that responded best in the current study (related to activity levels and emotionality) and those most sensitive to risperidone (Masi et al. 2001).

There are weaknesses in a naturalistic case-control study. Although the two samples were well matched, there was no control possible over their use of other interventions and resources. On the other hand, we were able to determine statistically that the two other types of common therapies (fish oil and nondrug "other" treatments, such as occupational therapy and educational assistance) did not account for the treatment effects reported here. Also, CGI scores did not vary with the minor variations in supplement subtype.

It is possible that the families who requested nonpharmaceutical assistance differed from those who asked for conventional treatment in ways that were not measured here. The micronutrient preparation is now available in powder form, but all 44 families in this sample had to be highly motivated to get their children to take all of the necessary capsules (as mentioned above, roughly 4 $18 /$ day). Some corroboration that these families were more highly motivated and focused on treatment options can be found in the fact that three times as many of them followed the psychiatrist's recommendation that they also use fish oil.

The weakness that poses the greatest threat to the data is perhaps the potential bias of the clinician, because he was not blinded. As indicated above, he did not have an a priori bias toward avoiding pharmaceutical interventions: He simply responded to the requests of parents. This chart review with retrospective matching of controls was initiated after he realized that patients with ASD treated with both types of interventions seemed to have done quite well, and he was curious enough to compare the data. After some initial comparisons, the database was sent for careful data analysis to two researchers (B.L. and B.J.K.) unfamiliar with the families or their treatment.

One of the strengths of this case-control study is that the sample was relatively large in comparison to many others (Masi et al. 2001; Canitano 2006; Amminger et al. 2007). Micronutrient treatment outperformed the results of other studies, including a multisite RCT (McCracken et al. 2002). The current report involved open-label data, which often exhibit stronger effects than RCTs; on the other hand, the matched control group was also open label.

The results reported in this case-control study are consistent with the mood-stabilizing effects documented for this same formula 
in a variety of other diagnoses: BPD, anxiety, $\mathrm{OCD}$, and so on (Kaplan et al. 2001; Popper 2001; Kaplan et al. 2002; Simmons 2002; Kaplan et al. 2004; Frazier et al. 2009; Gately and Kaplan, 2009; Rucklidge 2009). This similarity raises the question of cooccurring mood disorders in the sample in the current study. It can be difficult to diagnose mood disorders in children with severe communication deficits, although less so for the higher functioning ASD patients. For the current sample, the autism diagnosis was sufficient for clinical purposes, and no further diagnoses were made with these patients. Consequently, it is difficult to determine whether the observed changes were exerted through improvements in mood disorders or through an independent effect on autistic disorder. Future research that is carried out prospectively ought to distinguish between these two possibilities.

It has been said that if we want more evidence-based practice, we need more practice-based evidence. Although they do not carry the weight of an RCT, case-control studies with heterogeneous patients from medical practice can be instructive about whether or not particular approaches are promising. RCTs themselves have limitations for generalization to the clinic. For instance, it is not unusual to read an RCT that excluded any candidates who ever considered suicide, had multiple diagnoses, were using any benzodiazepine, were abusing any substance other than cigarettes, and so on. These entry criteria would exclude the majority of patients typically seen in a clinical practice, who are often caught up in thoughts of suicide, are abusing some substance, and do have multiple problems. Hence, RCTs can answer questions about efficacy only in relation to a placebo or other medication; they cannot answer questions about effectiveness in actual practice. In contrast, the present set of analyses addressed the question of effectiveness in a realistic, practical setting, comparing two quite disparate approaches to the management of ASD symptoms that are burdensome to families. The promising results reported herein warrant further exploration.

\section{Disclosures}

The authors have no financial ties to any pharmaceutical or nutritional company, including the one mentioned herein. All patients and families included in this study were under the clinical care of the first author (L.M.-M.), who takes full responsibility for the clinical management of the participants and the data collection. The second author (B.L.) was responsible for data analyses; the third and fourth authors (C.K. and S.P.) assisted with chart reviews; the fifth author (B.K.) consulted on the data and was responsible for the final manuscript.

\section{Acknowledgments}

We thank the Richmond Foundation of Santa Barbara, California, for its initial financial support to L.M.-M., Health Canada for its salary support for S.P., and the Alberta Children's Hospital Foundation for its ongoing support of B.L. and B.K. L.M.-M. thanks Janzen for providing Risperdal samples for families in financial need. Finally, we acknowledge the efforts of the participants and their families who willingly provided follow-up data beyond that which is usually required for clinical treatment.

\section{References}

Adams JB, Holloway C: Pilot study of a moderate dose multivitamin/ mineral supplement for children with autistic spectrum disorder. J Altern Complement Med 10:1033-1039, 2004.
Aman M, Arnold L, McDougle C, Vitiello B, Scahill L, Davies M, McCracken JT, Tierney E, Nash PL, Posey DJ, Chuang S, Martin A, Shah B, Gonzalez NM, Swiezy NB, Ritz L, Koenig K, McGough J, Ghuman JK, Lindsay RL. Acute and long-term safety and tolerability of risperidone in children with autism. J Child Adolesc Psychopharmacol 15:869-884, 2005.

Aman MG, Singh NN, Stewart AW, Field CJ: The aberrant behavior checklist: A behavior rating scale for the assessment of treatment effects. Am J Ment Defic 89:485-491, 1985.

American Psychiatric Association: Diagnostic and Statistical Manual of Mental Disorders, $4^{\text {th }}$ ed. (DSM-IV). Washington (DC): American Psychiatric Association, 1994.

Ames BN: The metabolic tune-up: Metabolic harmony and disease prevention. J Nutr 133:1544S-1548S), 2003.

Ames BN: A role for supplements in optimizing health: The metabolic tune-up. Arch Biochem Biophys 423:227-234, 2004.

Ames BN, Elson-Schwab I, Silver, EA: High-dose vitamin therapy stimulates variant enzymes with decreased coenzyme binding affinity (increased $\mathrm{Km}$ ): Relevance to genetic disease and polymorphisms. Am J Clin Nutr 75:616-658, 2002.

Amminger, GP, Berger, GE, Schafer, MR, Klier, C, Friedrich, MH, Feucht, M: Omega-3 fatty acids supplementation in children with autism: A double-blind randomized, placebo-controlled pilot study. Biol Psychiatry, 61:551-553, 2007.

Baghdadi A, Pascal C, Grisi S, Aussiloux C: Risk factors for selfinjurious behaviours among 222 young children with autistic disorders. J Intellect Disabil Res 47(Pt 8):622-627, 2003.

Campbell M, Palij M: Behavioral and cognitive measures used in psychopharmacological studies of infantile autism. Psychopharmacol Bull 21:1047-1053, 1985.

Canitano R: Self injurious behavior in autism: Clinical aspects and treatment with risperidone. J Neural Transm 113:425-431, 2006.

Fish B: Children's Psychiatric Rating Scale. Psychopharmacol Bull 21:753-764, 1985.

Frazier EA, Fristad MA, Arnold LE: Multinutrient supplement as treatment: Literature review and case report of a 12-year-old boy with bipolar disorder. J Child Adolesc Psychopharm 19:453-460, 2009.

Gardner A, Boles RG: Is a "mitochondrial psychiatry" in the future? A review. Curr Psychiatry Rev 1:255-271, 2005.

Gately D, Kaplan B: Database analysis of adults with bipolar disorder consuming a micronutrient formula. Clin Med:Psychiatry 4:3-16, 2009.

Gesch CB, Hammon SM, Hampson SE, Eves A, Crowder MJ: Influence of supplementary vitamins, minerals and essential fatty acids on the antisocial behaviour of young adult prisoners. $\mathrm{Br} \mathrm{J}$ Psychiatry 181:22-28, 2002.

Guy W (ed). ECDEU Assessment Manual for Psychopharmacology: Publication ADM 76-338. Washington (DC): U.S. Department of Healthand Human Services, 1976.

Hallahan B, Hibbeln JR, Davis JM, Garland MR: Omega-3 fatty acid supplementation in patients with recurrent self-harm. Single-centre double-blind randomised controlled trial. Br J Psychiatry 190:118122, 2007.

Itomura M, Hamazaki K, Sawazaki S, Kobayashi M, Terasawa K, Watanabe S, Hamazaki T. The effect of fish oil on physical aggression in schoolchildren-a randomized, double-blind, placebocontrolled trial. J Nutr Biochem 16:163-171, 2005.

James S, Melnyk S, Fuchs G, Reid T, Jernigan S, Pavliv O, Hubanks A, Gaylor DW. Efficacy of methylcobalamin and folinic acid treatment on glutathione redox status in children with autism. Am J Clin Nutr 89:425-430, 2009.

Kaplan BJ, Simpson JSA, Ferre RC, Gorman C, McMullen D, Crawford SG: Effective mood stabilization in bipolar disorder with 
a chelated mineral supplement. J Clin Psychiatry 62: 936-944, 2001.

Kaplan BJ, Crawford SG, Gardner B, Farrelly G: Treatment of mood lability and explosive rage with minerals and vitamins: Two case studies in children. J Child Adolesc Psychopharmacol 12:203-218, 2002.

Kaplan BJ, Fisher JE, Crawford SG, Field CJ, Kolb B: Improved mood and behavior during treatment with a mineral-vitamin supplement: An open-label case series. J Child Adolesc Psychopharmacol 14:115-122, 2004.

Kaplan BJ, Crawford S, Field C, Simpson JSA: Vitamins, minerals and mood: A scientific review. Psychol Bull 133:747-760, 2007.

Kato T, Kato N: Mitochondrial dysfunction in bipolar disorder. Bipolar Disorder 2:180-190, 2000.

Kemper KJ, Hood KL: Does pharmaceutical advertising affect journal publication about dietary supplements? BMC Complement Altern Med 8:11, 2008.

Konradi C, Eaton M, MacDonald ML, Walsh J, Benes FM, Heckers S: Molecular evidence for mitochondrial dysfunction in bipolar disorder. Arch Gen Psychiatry 61:300-308, 2004.

Marshburn EC, Aman MG: Factor validity and norms for the Aberrant Behavior Checklist in a community sample of children with mental retardation. J Autism Dev Disord 22:357-373, 1992.

Masi G, Cosenza A, Mucci M, Brovedani P: Open trial of risperidone in 24 young children with pervasive developmental disorders. J Am Acad Child Adolesc Psychiatry 40:1206-1214, 2001.

McCracken JT, McGough J, Shah B, Cronin P, Hong D, Aman MG, Arnold LE, Lindsay R, Nash P, Hollway J, McDougle CJ, Posey D, Swiezy N, Kohn A, Scahill L, Martin A, Koenig K, Volkmar F, Carroll D, Lancor A, Tierney E, Ghuman J, Gonzalez NM, Grados M, Vitiello B, Ritz L, Davies M, Robinson J, McMahon D; Research Units on Pediatric Psychopharmacology Autism Network. Risperidone in children with autism and serious behavioral problems. NEJM 347:314-321, 2002.

McDougle CJ, Stigler KA, Erickson CA, Posey DJ: Atypical antipsychotics in children and adolescents with autistic and other pervasive developmental disorders. J Clin Psychiatry 69(Suppl 4): 15-20, 2008.

Meguid N, Atta H, Gouda A, Khalil R: Role of polyunsaturated fatty acids in the management of Egyptian children with autism. Clin Biochem 41:1044-1048, 2008.
Mehl-Madrona L: Narrative Medicine: The Use of History and Story in the Healing Process. Rochester (Vermont): Bear \& Company, 2007.

Mousain-Bosc M, Roche M, Polge A, Pradal-Pra D, Rapin J, Bali JP: Improvement of neurobehavioral disorders in children supplemented with magnesium-vitamin B6. Magnesium Res 19:53-62, 2006.

Nye C, Brice A: Combined vitamin B6-magnesium treatment in autism spectrum disorder. Cochrane Database Syst Rev 4:CD003497, 2005.

Overall JE, Campbell M: Behavioral assessment of psychopathology in children: Infantile autism. J Clin Psychol 44:708-716, 1988.

Parikh MS, Kolevzon A, Hollander E: Psychopharmacology of aggression in children and adolescents with autism: A critical review of efficacy and tolerability. J Child Adolesc Psychopharmacol 18:157-178, 2008.

Popper CW: Do vitamins or minerals (apart from lithium) have moodstabilizing effects? J Clin Psychiatry 62:933-935, 2001.

Posey DJ, Stigler KA, Erickson CA, McDougle CJ: Antipsychotics in the treatment of autism. J Clin Invest 118:6-14, 2008.

Rimland B: Controversies in the treatment of autistic children: Vitamin and drug therapy. J Child Neurol 3(Suppl):S68-S72, 1988.

Rimland B, Callaway E, Dreyfus P: The effect of high doses of vitamin B6 on autistic children: A double-blind crossover study. Am J Psychiatry 135:472-475, 1978.

Rucklidge JJ: Successful treatment of OCD with a micronutrient formula following partial response to CBT: A case study. J Anxiety Dis 23:836-840.

Schopler E, Reichler RJ, DeVellis RF, Daly K: Toward objective classification of childhood autism: Childhood Autism Rating Scale (CARS). J Autism Dev Disord 10:91-103, 1980.

Simmons M: Nutritional approach to bipolar disorder. J Clin Psychiatry $64: 338,2002$.

Young LT: Is bipolar disorder a mitochondrial disease? J Psychiatry Neurosci 32:160-161, 2007.

Address correspondence to: Bonnie J. Kaplan, Ph.D. Behavioural Research Unit 2888 Shaganappi Trail NW Calgary, AB T3B 6A8 Canada

E-mail: bonnie.kaplan@albertahealthservices.ca 
